\title{
O modus vivendi na política rio-grandense: Uma análise das negociações iniciais que resultaram no pacto de 17 de janeiro de 1936
}

Modus vivendi in rio grande policy: An analysis of the initial negotiations which resulted in the agreement of January 17,1936

Resumo: Este artigo analisa o início do processo de pacificação da política riograndense, entre o final de 1934 até o início de 1935. Buscamos compreender como o bloco oposicionista, representado na Frente Única Gaúcha, e o governador Flores da Cunha, do PRL, passaram a costurar as divergências surgidas na Guerra Civil de 1932 e no exílio da FUG, passando a negociar aquilo que seria conhecido, em 1936, como modus vivendi. No entanto, o objetivo deste texto é procurar conhecer o que chamamos de primeira etapa deste processo. Isto é, analisar os primeiros diálogos em torno da pacificação da política regional. Para isso, analisamos trocas de telegramas presentes em arquivos particulares, notícias veiculadas na imprensa da época e dialogamos com a bibliografia já existente que aborda o tema.

Palavras-chave: FUG; Partido Republicano Liberal; Flores da Cunha.

\begin{abstract}
This article looks at the beginning of the peace process of the Rio Grande politics, from late 1934 until the beginning of 1935. We seek to understand how the opposition bloc, represented the United Front Gaucho, and the governor Flores da Cunha, the PRL, passed to sew the differences arising in the Civil War of 1932 and the exile of FUG, going to negotiate what would be known in 1936 as a modus vivendi. However, the objective of this text is to seek to know what we call the first stage of this process. That is, to analyze the early dialogues around the pacification of regional policy. For this, we analyze telegrams exchanges present in private files, reports in the press of the time and we dialogue with existing literature that addresses the issue.
\end{abstract}

Keywords: FUG; Liberal Republican Party; Flores da Cunha.

${ }^{*}$ Doutorando em História - PUCRS/ CAPES 


\section{ESCLARECENDO O OBJETO: JUSTIFICATIVA, PROBLEMAS, APONTAMENTOS}

Procuraremos, neste texto, analisar o início do processo de pacificação da política regional, o qual desembocou, em 1936, na assinatura do pacto regional intitulado modus vivendi, entre PRL e FUG. Nesse sentido, para situar o leitor no contexto, vale destacar alguns aspectos inerentes a política regional do pós revolução de 1930. Se as correntes políticas do Rio Grande do Sul, representadas pelo Partido Republicano Rio-grandense e Partido Libertador, se unificaram e contribuíram para a ascensão de Getúlio Vargas ao Palácio do Catete naquilo que ficou conhecido como $o$ milagre do Rio Grande do Sul (CORTES, 2007), logo em seguida uma série de insatisfações eclodiram no PRR e PL com a orientação impressa por Vargas em nível federal.

Isto fizera com que ambos os partidos ${ }^{1}$, unificados em uma Frente Única Gaúcha desde antes do movimento revolucionário de 1930, dessem apoio aos insurretos paulistas em 1932. ${ }^{2}$ Apesar de contarem com o apoio de Flores da Cunha que, desde 1930, era o interventor no estado, este, na hora $H$, acabou sendo influenciado por Oswaldo Aranha, que conseguiu convencê-lo a ficar ao lado do governo provisório, debelando os fracos e escassos levantes provocados pelos frenteunistas, que foram para o exílio no Uruguai, Argentina e Portugal. Isso

\footnotetext{
1 Neste texto, "partido" será entendido como agrupamentos de pessoas que visam "conquistar e preservar o poder", conforme Motta. Além dele, para não considerar de forma tão simples o que é extremamente complexo, levamos em consideração a assertiva de Serge Berstein. Para esse autor, um partido é onde ocorre a mediação política e, "entre o programa político e as circunstâncias que o originam, há uma distância considerável, porque passamos então do domínio do concreto para o do discurso, que comporta uma expressão das ideias e uma linguagem codificadas. É no espaço entre o problema e o discurso que se situa a mediação política e esta é obra das forças políticas, que têm como uma de suas funções primordiais precisamente articular, na linguagem que lhes é própria, as necessidades ou as aspirações mais ou menos confusas das populações. Por isso a mediação política assume o aspecto de uma tradução e, como esta, exibe maior ou menor fidelidade ao modelo que pretende exprimir". Para ele, um partido também pode ser definido como "uma reunião de homens em torno de um objetivo comum" composto por gerações distintas. Cf. MOTTA (2009, p. 11) e BERSTEIN (2003, p. 61).

${ }^{2}$ Sobre o apoio da política rio-grandense ao movimento "constitucionalista" de 1932, cf.: LAPUENTE, Rafael Saraiva. 'Estou forte e manterei a ordem. Reagiremos!': um estudo a respeito da política riograndense por meio da 'revolução' de 1932. Revista do Instituto Histórico e Geográfico. Porto Alegre, n. 149, dez. 2015, p. 129-147 e LAPUENTE, Rafael Saraiva. 'Ficaê com Rio Grande e sede o seu galhardo conductor na nova crusada redemptora': o papel do Rio Grande do Sul na 'Revolução' de 1932 - antecedentes e consequências. In: BRUM, Cristiano Enrique de et al (orgs.). O historiador e suas tecnologias. Porto Alegre: Memorial do Ministério Público do Rio Grande do Sul, 2015.
} 


\section{Revista Brasileira de História \& Ciências Sociais - RBHCS}

Vol. $8 \mathrm{~N}^{\circ}$ 16, Julho - Dezembro de 2016

acusando Vargas de ser um "ditador" e Flores da Cunha um "traidor", por ter, supostamente, dado a sua palavra de que acompanharia a FUG. Por estes países permaneceram, exceto Borges de Medeiros em seu exílio interno no Recife, até que fossem anistiados, em 1934, após um período de conspirações armadas e vigilância pela interventoria florista e governo provisório. Elegeriam, portanto, Getúlio Vargas como o adversário a ser batido, e Flores da Cunha, que após o dissídio fundara o Partido Republicano Liberal, aliado ao Catete e adversário dos frenteunistas (LAPUENTE, 2015).

A importância deste tema se dá, especialmente, porque o processo de pacificação da política regional, tema presente com mais fôlego desde 1934, além de pouco estudado pela historiografia sulina, marcou uma importante aproximação entre FUG e Flores da Cunha. Isto é, vemos esse objeto como um ponto de intersecção, entre um período marcado por conspirações armadas e exílio de tradicionais lideranças políticas do Rio Grande do Sul desde a Primeira República, e de reaproximação entre estas correntes na medida em que Flores da Cunha, de garantia de ordem e fidelidade ao Catete, passa a se distanciar de Getúlio Vargas, contexto cujo qual impulsionaria esta aproximação a partir de setembro de 1935 .

Optamos por um recorte regional no processo de análise, pois, assim como Janaína Amado (1990), acreditamos que esta abordagem viabiliza "novas óticas de análise ao estudo de cunho nacional, podendo apresentar todas as questões fundamentais da história" a partir do enfoque, "que faz aflorar o específico, o próprio, o particular”. Ana Reckziegel (2010) segue uma via parecida. Para ela, o estudo do regional apresenta todas as temáticas relacionadas à história dita 'nacional', mas sob uma ótica que ressalta a especificidade, as diferenças e a multiplicidade, pois a história nacional generaliza e a regional particulariza. A autora ainda afirma que a história regional por muito tempo foi vista como algo "menor", visão que ficou em xeque com o esgotamento das macro abordagens.

Deste modo, dividiremos este texto em duas partes. Em um primeiro momento, procuraremos demonstrar como ressurgiu a ideia de pacificação da política regional em meio as eleições de 1934 para, posteriormente, analisar como ocorreram as conversações "formais" visando selar este acordo, até a sua negativa, nesta que chamaremos de primeira etapa do processo de pacificação. A segunda 
etapa, que consolida a assinatura do pacto, merece um estudo a parte, embora, panoramicamente, a abordaremos neste texto.

\section{2. "UM HOMEM QUE SE TENHA MANTIDO ESTRANHO ÀS ÚLTIMAS CONTENDAS": AS CONVERSAS POR UM ACORDO EM MEIO AO PROCESSO ELEITORAL DE 1934}

Apesar de ter sido em 1935 que o processo de pacificação ganhou impulso, as tratativas de unificação não começaram neste ano. Podemos dizer que o situacionismo estadual buscou, em diferentes momentos pós-guerra civil, acordos com oposição, sempre sem sucesso. É importante ressaltar que, caso ocorresse a unificação entre a FUG e o PRL, o papel de Flores da Cunha não seria mais o de um mero administrador, com poucos poderes de decisão nos assuntos políticopartidários, como havia sido nos primeiros anos de interventoria. A situação pós1932 alterou completamente essa conjuntura, e Flores da Cunha era o chefe do principal partido político naquele momento, como as eleições de 1933, 1934, e também a de 1935, mostraram.

Desta forma, Flores da Cunha, além de buscar apaziguar os ânimos já no fim da guerra civil, com Maurício Cardoso, manteria conversas com a oposição em outros momentos, inclusive quando estavam no exílio, no auge das conspirações armadas contra seu governo, e até mesmo contra sua vida, ainda que sabendo de tudo isso. Assim, destacamos um trecho d'A Federação, após as eleições de maio de 1933, afirmando que Flores da Cunha prossegue no "generoso propósito" de "levar a bom termo e o mais depressa possível a pacificação dos espíritos do Rio Grande do Sul”, o que não ocorria devido à oposição partida dos "beneficiários da munificência", apelando para que houvesse "um movimento simultâneo e de boa vontade. É preciso que aqueles que devem receber venham ao encontro de quem quer dar". Ressalvando o lado superlativo nesse trecho, a alegação do jornal é um exemplo das tentativas de aproximação que partiam do governador nesse período, assim como no ano seguinte, onde, em um discurso quando visitou o município de Uruguaiana, fez alusão à pacificação da política regional, mas em um tom pouco distinto, mais hostil do que aquele pronunciado em 1933. Falando a respeito do tema, afirmou não ser ele empecilho "a qualquer movimento pacificador, e que, para tanto, se submeteria 


\section{Revista Brasileira de História \& Ciências Sociais - RBHCS}

Vol. $8 \mathrm{~N}^{\mathrm{o}}$ 16, Julho - Dezembro de 2016

mesmo a todos os sacrifícios. 'Mas não confundam - acrescentou - confraternização com cambalachos políticos ou troca e partilha de posições"”.3

Vemos no parágrafo acima que é Flores da Cunha quem procura a Frente Única Gaúcha, e toca no tema da pacificação regional, fato que se contrapõe à afirmação de Hélgio Trindade (1980, p. 251-252) quando diz ser Flores da Cunha quem “aceita barganhar com a FUG”, por sentir na política anti-extremista de Vargas uma ameaça "centralista e autoritária”, e que é da FUG que parte "a tentativa de reaproximação [...] com o governo Flores da Cunha”. No primeiro caso, é uma "meia verdade", pois antes do rompimento com o Catete, Flores da Cunha procurou a oposição regional, tendo o apoio de Getúlio Vargas, e recebendo quase sempre a negativa dos frenteunistas. Já a segunda afirmação é inconsistente. Isso fica demonstrado pelo fato de que o único movimento de um libertador, nesse sentido, foi em março de 1935, mas tratou-se de uma atitude particular e independente, e não da direção da FUG.

Mas a ideia de "pacificação" começou a ganhar força durante a campanha eleitoral de 1934, quando ataques, acusações, assassinatos e fraudes estiveram muito presentes. Apesar dessas procuras formais anteriores, o ressurgimento do tema ocorreu de maneira informal, ou seja, sem um encontro para debater, frente a frente, pontos de vista que levassem FUG-PRL a firmar um pacto de apaziguamento. $\mathrm{O}$ princípio das negociações, em setembro de 1934, poderia ser chamado de etapa de uso eleitoral, em função de não haver um debate sério e interessado, pelo qual se quisesse, realmente, assinar um acordo formal. Mesmo que o tema da pacificação tenha sido abordado com objetivos eleitorais, ainda assim não deixou de ser relevante, pois propiciou conversas mais sérias sobre o tema no futuro, criando uma conjuntura favorável para discussão.

O início disso se deu em uma viagem de Flores da Cunha a Santa Maria, onde, em propaganda eleitoral, declarou ser favorável à reconciliação da família gaúcha, mas alegava que tal medida seria impossível em função das negativas partidas da FUG. ${ }^{4}$ Esse apelo de Flores da Cunha, que novamente culpava a Frente Única Gaúcha, e a responsabilizava por não perseguir o mesmo objetivo, teria resposta imediata de Raul Pilla. Falando para a "Mocidade Frenteunista", a militância jovem

\footnotetext{
3 A Federação. Porto Alegre, HDBN, 25.05.1933 e 30.04.1934.

4 Correio do Povo, Porto Alegre, MCSHJC, 01.09.1934.
} 
da FUG, Pilla faria aquilo que seria conhecido como o Discurso do Teatro Coliseu, famoso por ser o primeiro pronunciamento em público de um frenteunista sobre essa questão. Nele, o chefe do PL questionou:

Tem-se falado, fala-se continuamente na pacificação do Rio Grande. Que espírito bem formado não a desejará? Mas, senhores, concedido que pudesse haver paz sem liberdade, paz sem garantias concedidas indistintamente a todos os cidadãos, paz sem a proscrição da violência e de distinções odiosas, seria esta pacificação digna do centenário farroupilha, que se pretende comemorar no ano próximo? Iriamos fazer a paz da submissão, a paz da subserviência para comemorar os grandiosos feitos daqueles heróis da liberdade?5

Raul Pilla também buscou "engessar" o pronunciamento do interventor, utilizando suas declarações. Nesse sentido, relembrava que Flores da Cunha afirmou publicamente não ser um obstáculo ao "congraçamento da família rio-grandense e até se daria em holocausto a semelhante inspiração". Pilla prosseguiu, afirmando que "os homens da Frente Única também não serão obstáculo, porque não pleiteiam cargos, não desejam posições e aspiram apenas a que o Rio Grande possa ainda vir a dar ao país um exemplo de verdadeira democracia”. Negando “capitulação” ao situacionismo, assegurava que os frenteunistas "não poderão concorrer para a debilitação da vida partidária rio-grandense, porque os partidos são necessários ao funcionamento normal da democracia”. Desta forma, Pilla proporia a substituição da candidatura de Flores da Cunha por "um homem que se tenha mantido estranho às últimas contendas", que "seja no governo não o chefe de um partido, mas o magistrado de um povo inteiro"6, sustentando a ideia de uma candidatura neutra como condição para a pacificação por toda a elite partidária da FUG.

Rebatendo a assertiva de Pilla, Flores da Cunha se contradiria, pois agora rechaçava a ideia de renunciar, alegando que essa exigência, partindo da FUG, não passava de uma tentativa de escapar da provável derrota eleitoral, afirmando que "a renúncia que ela exige de mim é unicamente esta: que eu lhe dê uma saída para salvar-se”. Também se defendeu das acusações de que seria "insincero quando afirmo que para bem da minha terra, para bem do Rio Grande, não hesitarei em me oferecer mesmo em holocausto". No meio dos debates, Pilla, no dia seguinte, rebateu, declarando que se o interventor estivesse disposto a "pacificar" o Rio Grande do Sul,

\footnotetext{
5 Correio do Povo, Porto Alegre, MCSHJC, 20.09.1934.
}

6 Correio do Povo, Porto Alegre, MCSHJC, 20.09.1934. 


\section{Revista Brasileira de História \& Ciências Sociais - RBHCS}

Vol. $8 \mathrm{~N}^{\circ}$ 16, Julho - Dezembro de 2016

renunciaria, e que a FUG não mudaria sua exigência. Internamente, a João Neves da Fontoura, ele dissera que a expectativa de permanência de Flores da Cunha por mais quatro anos era "simplesmente aterradora", e que só se pronunciava acerca da "pacificação" nos termos do Discurso do Teatro Coliseu, ele mencionava que, com a continuidade do florismo, analisava ser impossível participar do pleito municipal de 1935, sendo "materialmente impossível fazê-lo".7

Nessa narrativa inicial, podemos perceber que o assunto só era debatido através de discursos e declarações na imprensa regional, e de outras localidades do país, utilizada exclusivamente como um argumento de combate e desqualificação do adversário, não sendo encarada como uma ideia efetiva. Nenhum dos dois grupos, em pleno período eleitoral, tinha interesses em uma aliança conciliatória, apesar das declarações públicas preconizarem o contrário. Também seria completamente ambíguo falar em pacificação, enquanto havia uma campanha marcada por virulentos ataques e acusações, que não propiciavam uma conjuntura favorável para entendimentos. De 1932 até então, é bem verdade que Flores da Cunha procurou outras vezes a Frente Única Gaúcha para "pacificar” a política regional. Isto é, buscando uma aliança política. Mas, contraditoriamente, o PRL não abriu mão de jogar, nesse intervalo, o peso do seu aparato coercitivo contra a FUG, procurando a manutenção do florismo no poder, e influindo na inviabilidade da propalada "aproximação".

Além disso, era evidente que, enquanto o florismo buscava passar a imagem de pacifista, a FUG não tinha outra intenção a não ser enfraquecer o PRL na eleição, e, principalmente, impedir o continuísmo de Flores da Cunha à frente do governo estadual. No entanto, mesmo passando o pleito de outubro, a FUG não deixaria de lado a tentativa de retirar a candidatura de Flores da Cunha. Já ele próprio, agora acuado com o argumento da renúncia, buscava afastar a ideia de remoção da própria candidatura. Isto é, sua renúncia não seria uma pauta aceitável na mesa de negociações para um modus vivendi.

A bem da verdade, encontramos uma única conversa frente a frente entre FUG-PRL em 1934, mas que deu ênfase especial à diminuição dos ataques na campanha eleitoral "sem as grosserias que continuam", realizadas por João Carlos

7 A Federação, Porto Alegre, HDBN, 25.09.1934; Correio do Povo, Porto Alegre, MCSHJC, 26.09.1934; ARP, s.d., NUPERGS, doc. $\mathrm{n}^{0}$ 002/1279. 


\section{Revista Brasileira de História \& Ciências Sociais - RBHCS}

Vol. $8 \mathrm{~N}^{\mathrm{o}}$ 16, Julho - Dezembro de 2016

Machado, do PRL, e Firmino Paim Filho, do PRR. Num telegrama, Machado afirmava que Paim levou, em reunião da FUG, a pauta da pacificação gaúcha para o próximo ano, tendo o apoio de Maurício Cardoso, Martins Costa e do Arcebispo. 8 Mas, sendo o telegrama datado de agosto de 1934, o que percebemos posteriormente foi justamente o contrário daquilo que havia sido proposto: não houve avanços, até então, na pacificação, e nem abrandamento na campanha eleitoral.

Todavia, especulações acerca da pacificação regional cresceram em novembro. Isso porque, neste mês, Getúlio Vargas visitou o Rio Grande do Sul, e imediatamente o jornal $O$ Globo levantou a hipótese da visita do presidente estar vinculada ao interesse de Getúlio Vargas na "pacificação da família rio-grandense", no caso, não mirando especificamente uma fusão, mas, sim, buscando elevar o tom do jocoso debate político. Ainda assim, é pouco provável que essa versão seja realmente consistente. Ao menos, os telegramas trocados no período existentes no Arquivo Getúlio Vargas, do CPDOC, bem como seu Diário não mencionam esse tipo de tratativa em sua visita, que também não reflete em avanços, apesar de, perguntado a respeito, respondeu: "é bem verdade que para mim não poderia deixar de ser muito agradável a pacificação do Rio Grande e de todos os rio-grandenses”. 9

Em contrapartida, é citada uma procura realizada por um intermediário de Raul Pilla, em que este dizia que o líder do PL "havia mudado de opinião a meu respeito, compreendia que não fizera um juízo exato da situação, estava disposto a uma aproximação com o governo federal, e que isto seria fácil, bastaria substituir a candidatura do Flores à presidência do estado" (VARGAS, 1995, p. 344-345). O quase "pedido de desculpas" realizado por Pilla, visando a ter como moeda de troca a retirada do nome de Flores da Cunha, mostrou o início do jogo duplo realizado pela FUG. Enquanto a aliança frenteunista obtinha a liderança na oposição ao governo federal, não deixava, ao mesmo tempo, de buscar entendimentos com Vargas para resolver suas divergências em âmbito estadual. A conversa feita por um terceiro, por sua vez, também não pode ser descartada do objetivo de despistar a ampla cobertura jornalística que a estada do presidente ganhou nas páginas dos periódicos do estado. ${ }^{10}$

8 AFC, 08.08.1934, NUPERGS, doc. $\mathrm{n}^{0}$ 003/875.

9 Correio do Povo, Porto Alegre, MCSHJC, o8 e 24.11.1934.

${ }_{10}$ Qualquer movimento ou deslocamento era associado a tratativas de pacificação pela imprensa regional. Nesse sentido, é exemplar a cobertura dada à viagem de Flores da Cunha para São Borja, 
Já o presidente analisava com cautela o cenário regional, afirmando que essa medida não era fácil, "primeiro, porque o Flores havia aceito sua candidatura, já apresentada pelo partido, e não iria recuar; segundo, porque ele organizara uma agremiação partidária de que era chefe, e este não se conformaria com a modificação de compromissos recíprocos já assumidos”. Analisando a medida, Getúlio Vargas (1995, 344; 345) afirmou que isso seria "agradar a uns para desagradar a outros", não tendo "motivos contra o Flores, que era para mim uma garantia de ordem no Rio Grande do Sul. [...]. Atendi a várias visitas individuais e de comissões, bem como o diretório da Frente Única, que me trouxe uma representação contra o interventor”.

Essa representação acabou tendo ampla divulgação pela imprensa. Foi uma nota denunciando a truculência oficial, assinada por Raul Pilla e Borges de Medeiros, delatando os ataques partidos do PRL, relatando assassinatos e atentados contra correligionários da FUG no interior do estado, e denunciava o incêndio d'O Libertador, o boicote oficial ao Correio do Povo, a substituição de prefeitos, e transferências, demissões e aposentadorias compulsórias realizadas por membros ligados ao partido governista, com funcionários públicos que apoiavam a campanha dos frenteunistas. ${ }^{11}$

Por outro lado, questionamos: como poderia a FUG, após toda a postura oposicionista que teve contra Vargas, e sofrendo através dele ostracismo, exílio, perseguição, participando durante esses dois anos de conspirações para sua derrubada, e tendo, por meio do Catete, todas as suas ações vigiadas e boicotadas, buscar se aproximar de forma tão visível para enfrentar o florismo no Rio Grande do Sul? Como o contexto de disputas políticas dentro do Rio Grande do Sul fez Getúlio Vargas passar, para a FUG, de "inimigo número 1", do "ditador de 1932", para um potencial aliado para combater (ou inibir) o interventor? Afinal, "valia tudo" para os frenteunistas derrubarem Flores da Cunha? E a relação com as oposições em nível nacional, como ficaria em função desta aproximação?

Dentro desse panorama, seria muito improvável que a busca por uma aliança com Vargas passasse ilesa de contestações nas fileiras da Frente Única. Em dezembro de 1934, João Neves da Fontoura telegrafou para Batista Lusardo, alegando que a

onde estava Vargas com a família, tendo as matérias na imprensa associado o deslocamento de Flores com as tratativas de pacificação da política regional. Ao menos o Diário de Vargas, no mesmo período, não menciona esse assunto como conversa, nem mesmo seus telegramas. Cf. VARGAS (1995, p. 344345); Correio do Povo, Porto Alegre, MCSHJC, 18.12.1934.

${ }^{11}$ Correio do Povo, Porto Alegre, MCSHJC, 20.12.1934. 
representação feita a Getúlio "surpreendeu-me e desgostou-me”. Assim, João Neves considerava "um erro de consequências graves", que caiu "como uma bomba no seio dos últimos crentes”. Questionando a representação contra as arbitrariedades do governo florista ${ }^{12}$, comparou a situação do Rio Grande do Sul com a de outros estados, afirmando que "os baianos apanham na rua e não vão ao Catete; idem os norte-rio-grandenses, os paranaenses etc.”, alegando que "a palavra de ordem era ignorar o Getúlio. Afinal, com quem rompemos em 32? Com Flores ou com Getúlio? Por que combatemos inicialmente o Flores senão porque ficou com Getúlio?”, e que essa atitude havia retirado "a pedra fundamental na oposição parlamentar. E que vantagens tiramos? Nenhuma, nenhumíssima”. ${ }^{13}$

Como vimos, houve desconforto na aproximação da FUG com Vargas, e, por aquilo que se pode decifrar do telegrama, é possível dizer que havia um acordo no seio frenteunista de ignorar a visita do presidente ao Rio Grande do Sul, que foi rompido por essa representação. O descontentamento também ocorria devido à possível perda do prestígio da FUG entre oposições em nível federal. Essa adesão, malvista pelas demais oposições, poderia colocar em xeque a preponderância que a FUG vinha exercendo como contraponto ao governo Vargas no cenário nacional, o que efetivamente ocorreu.

Era compreensível a indignação em nível federal, sobretudo, porque as oposições de outros estados vinham denunciando os interventores e apontando Vargas como responsável pelos problemas ocorridos nos estados por meio do parlamento (MOURELLE, 2015). Por isso, acreditamos que essa conjuntura no Legislativo bem explica por que a repercussão das conversas entre FUG e Vargas não tenha sido tão positiva no interior do bloco oposicionista federal. Mas ainda assim, a preponderância da FUG neste seguiu. E as conversas para a pacificação regional, levadas a efeito logo após o pleito de 1934, gradativamente teriam tons menos hostis, visando levar FUG e PRL a uma aliança conciliatória.

\footnotetext{
12 Diante do sentimento de revolta contra a posição do interventor em 1932, agudizado com o ocorrido nos períodos eleitorais, parecia que o rompimento não tinha volta. Por isso, Viriato Vargas aconselhava a Getúlio afastar Flores da Cunha da interventoria, e substitui-lo por Oswaldo Aranha: "Acho porém que o Osvaldo na interventoria, ainda prestaria melhores serviços do que aí no ministério. O Flores foi o que lutou, foi o que venceu, foi o que feriu e contra o qual há portanto resabios [sic] e amarguras da luta. Já o Osvaldo está noutro caso. Estava longe, não atuou aqui durante a luta e, com sua conhecida habilidade e simpatia, é capaz de trazer para o PRL os restos do PRR". AGV, 09.01.1934, CPDOC, GV c 1934.01.09/1.

${ }^{13}$ ARP, 31.12.1934, NUPERGS, doc. $\mathrm{n}^{0}$ 002/1121.
} 
Portanto, é saindo do contexto eleitoral, diminuindo a tensão e as rivalidades entre FUG e PRL que se passaria a ter melhores condições para conversas no Rio Grande do Sul e no cenário nacional, com a definição dos deputados federais em substituição aos constituintes, o mesmo acontecendo com os constituintes estaduais.

\section{A CANDIDATURA INDIRETA DE FLORES DA CUNHA E OS 11 PONTOS DA FUG}

A rivalidade entre Góis Monteiro e Flores da Cunha já tinha antecedentes, e seria cada vez mais aguda, já que os dois eram "líderes de filosofias incompatíveis", como bem definiu Carlos Cortés. Além de se intrometer nos assuntos do Exército, Góis Monteiro não concordava com a manutenção dos corpos provisórios por Flores da Cunha. Estes grupos armados mantidos pelo governador no Rio Grande do Sul foram tachados pelo ministro da guerra como "reserva militar irregular a serviço de caprichos caudilhescos”. Já o líder político rio-grandense retribuía as acusações, adjetivando Góis Monteiro de "bonapartista" (CORTÉS, 2007, p. 109; COUTINHO, 1956, p. 254; 158). ${ }^{14}$ Essa troca de farpas exemplifica parcialmente a rivalidade entre os dois.

Foi justamente no contexto de dissídio entre eles que Góis Monteiro intermediou o encontro de Getúlio Vargas com Lindolfo Collor. Sua atitude, naquele momento, pode ser vista como uma maneira de buscar fortalecer a oposição interna ao governo de Flores, visando a enfraquecer a soberania política do PRL no estado, e aproximando a FUG de Vargas. Collor dissera a Getúlio Vargas que as conversas havidas para a pacificação se deram por insistência e iniciativa de Flores da Cunha, mas que esbarravam na recusa dos frenteunistas em aceitar sua candidatura a governador do estado, o que desembocaria em uma "simples adesão". Vargas (1995, p. 378), no entanto, respondeu que “as aspirações ideológicas da Frente Única que já não estavam realizadas estavam em vias de realização. Nessas condições, fazer

\footnotetext{
${ }^{14}$ A questão mineira refere-se a conturbada sucessão pós-morte de Olegário Maciel, que dividiu Flores da Cunha e Oswaldo Aranha em 1933, já que o primeiro defendia a nomeação de Gustavo Capanema e o segundo postulava a escolha de Virgílio de Melo Franco para a interventoria mineira. A saída encontrada por Vargas foi a escolha do ainda inexpressivo Benedito Valadares, neutralizando ambos e, também, o político mineiro Antônio Carlos de Andrada.
} 


\section{Revista Brasileira de História \& Ciências Sociais - RBHCS}

Vol. $8 \mathrm{~N}^{\mathrm{o}}$ 16, Julho - Dezembro de 2016

questão do nome do Flores seria conduzir um assunto que poderia trazer tantos benefícios ao país a uma questão pessoal”.

Ao mesmo tempo em que Vargas se esquivava com a conversa de Collor, também não deixou de ouvir o membro do PRR. Este propunha a Vargas uma aproximação com o seu governo, tendo, ao menos verbalmente, a anuência do presidente com o tema. A hipótese de uma “pacificação nacional” em torno do governo Vargas englobaria uma reorganização ministerial, da qual a oposição faria parte. "Respondi-lhe que aceitava a discussão da tese e sugeria mais a hipótese de formação de um grande partido nacional, para o qual eles entrariam, e que traçaria um programa político e administrativo que seria rigorosamente executado”. Lindolfo Collor, deste modo, aceitou inicialmente a ideia, ficando "de ouvir seus companheiros e, até mesmo, se fosse necessário, ir ao Rio Grande e depois responder-me”. (VARGAS, 1995, p. 378).

Mesmo que essa conversa, neste momento, não fosse levada adiante, fica nítida a postura de Getúlio Vargas: mesmo tendo Flores como um importante aliado, ele não fechou a porta para negociar com a oposição ao seu governo. Vargas até mesmo propôs formar um partido de abrangência nacional, uma ideia que nos anos 1930 esteve sempre presente, e ao lado da Frente Única Gaúcha. Junto com ela, seria recomposto o ministério do governo provisório. Por outro lado, não se pode descartar que, apesar de Vargas confiar em Flores da Cunha, as frequentes instabilidades nas ações do chefe político do Rio Grande do Sul deixavam o governo em uma situação ambígua. Afinal, se Flores da Cunha pressionava pelo atendimento de suas exigências, com a ameaça de demissão, e hostilizava o ministro da guerra, também um afastamento completo de Vargas da FUG, segunda força política do estado, podia causar problemas para o presidente, com as duas forças políticas do estado hostilizando o governo central, caso as querelas de Flores da Cunha se transformassem em uma cisão política definitiva.

A procura de Lindolfo Collor a Vargas, ocorrida em 9 de abril, foi justamente no momento em que FUG e PRL negociavam a pacificação, dessa vez, formalmente. A postura ambígua foi corroborada pelo caráter "secreto" do encontro, já que apenas no mês seguinte a imprensa saberia dele, acentuando seu caráter sigiloso, e alegando que a reunião entre os dois teria como pauta a pacificação do Rio Grande do Sul, sendo realizada por intermédio de Vargas e, assim sendo, enfraquecendo Flores da 
Cunha. ${ }^{15}$ Essa afirmação do Diário Carioca foi desmentida pela entrevista de Collor, que, além de negar o caráter secreto, afirmou:

Só indiretamente se tratou, nesse encontro, da política do Grande do Sul [sic], isso mesmo sem preocupação de ser a favor ou contra quem quer que seja. [...]. O meu ponto de vista a respeito da pacificação do Rio Grande, que eu considero patriótico e justo não sofreu nenhuma modificação depois de minha entrevista com o Presidente da República. O que eu sustento e volto a dizer, é que sou contrário a acordos regionais, mesmo a qualquer entendimento federal, salvo para a hipótese de se operar entre o governo da república e a oposição um verdadeiro 'sursum corda' nacional, de forma que aqueles que se afastaram da situação para melhor servir o país e aos quais se juntaram a outras formas da opinião. ${ }^{16}$

$\mathrm{Na}$ entrevista de Lindolfo Collor, fica muito evidente o contraste entre aquilo que foi conversado com Vargas e o que foi alegado pelo ex-ministro do trabalho. Nesse sentido, mesmo que em prejuízo de nossa narrativa, gostaríamos de fazer uma breve reflexão sobre o artifício retórico utilizado por Collor. Sua ação de despiste se enquadra naquilo que Patrick Charaudeau (2004) chama de máscaras no ato de comunicação, ou seja, ele utilizou na frase a imagem que achou mais conveniente para persuadir, no caso, o interrogador e o público do periódico, ou, caso o encontro com Vargas pudesse trazer algum mal-estar entre as oposições, convencer seus aliados políticos de que não teve como assunto nada vinculado a política. Assim, levando-se em consideração o fato de que Lindolfo Collor, e todos os demais políticos aqui estudados, têm no uso das palavras sua principal forma de ação, pois dentro do universo do político, são elas que garantem o espaço de discussão, ação e persuasão, que asseguram aos atos políticos debates, trocas de opiniões e busca pelo convencimento.

Isto é, procurando persuadir que sua reunião com Getúlio Vargas não teve caráter político, mesmo que, efetivamente, houvesse, Collor tentou desviar os boatos que eram confirmados pela imprensa, e que, na verdade, apenas chancelavam aquilo que Vargas relatou em seu Diário.

Essa estratégia pode estar atrelada às negociações que envolviam a composição política rio-grandense, para não atrapalhar as conversas entre FUG e PRL. Cronologicamente, se faz necessário recuar alguns meses, para compreender o reinício das conversas em torno do pacto rio-grandense. Aparentemente, os diálogos

${ }_{15}$ Correio do Povo, Porto Alegre, MCSHJC, 14.05.1935.

${ }^{16}$ Correio do Povo, Porto Alegre, MCSHJC, 14.05.1935. 


\section{Revista Brasileira de História \& Ciências Sociais - RBHCS}

Vol. $8 \mathrm{~N}^{\circ}$ 16, Julho - Dezembro de 2016

iniciaram através de uma reconciliação pessoal entre Flores da Cunha com Sinval Saldanha, ex-secretário seu e de Borges de Medeiros, de quem também era genro. $\mathrm{O}$ encontro foi questionado pela imprensa. Respondendo aos Diários Associados, Flores da Cunha afirmou que realmente se encontrou com Sinval Saldanha, na residência de seu filho, Luiz Flores da Cunha, mas que "esse encontro, todo de caráter pessoal, não teve outra inspiração ou finalidade além do reatamento de antigas e boas relações de amizade. A esse fato se limita o que de positivo ocorreu”. Prosseguindo, afirmou que "serão sempre nobres e salutares todas as ações visando ou promovendo a reconciliação do povo rio-grandense fora de conchavos ou preocupações subalternas". ${ }^{17}$

Também, em telegrama particular para Getúlio Vargas, faria uma afirmação semelhante. Segundo Flores, a reunião entre ambos, na casa de seu filho, ocorreu no sentido de "congraçamento [da] nossa gente", mas sendo essa "simples reconciliação pessoal". Afirmava o interventor estar informado que "Pilla, Neves, Color [sic], Assis, Bruno Lima, Torely, Lucídio Ramos, Gonçalves Viana e outros libertadores desejam pacificação". Prosseguindo, destacava a "oposição por parte de Borges, Maurício, Luzardo, e de poucos mais, partidários da ação violenta”, além do que, atacava Borges de Medeiros: "parece que solitário do Irapuá está delirante de despeito e ódio. Exige que eu retire minha candidatura e abandone a Interventoria”. ${ }^{18}$

Quatro dias depois, Getúlio Vargas respondeu a comunicação de Flores da Cunha. Nela, além de demonstrar simpatia pelo andamento das conversações, deu conselhos de como o interventor deveria agir para avançar nas tratativas, buscando romper os entraves que se levantavam. "Se conseguires fragmentar [o] bloco oposicionista, obtendo apoio [do] elemento mais ativo e inteligente terás obtido notável êxito". ${ }^{19}$

O interventor, em meio à proximidade da instalação da constituinte, encararia o obstáculo de desarticular Borges de Medeiros, que parecia ser o empecilho mais difícil. Em telegrama para a redação do jornal $A$ Noite, por exemplo, o chefe do PRR era seco e direto ao responder sobre o assunto: "considero inaceitável a fórmula

\footnotetext{
${ }_{17}$ APSS/BM, 22.03.1935, AHRGS, cx. 60, maço 97.

${ }^{18}$ AGV, 23.03.1935, CPDOC, GV c 1935.03.23. Tecnicamente, o correto seria Batista Lusardo, com s, e não com $z$. Contudo, alguns poucos telegramas mencionam com a letra $z$, como este trecho citado, conforme já foi visto no texto. Ressalto isso para o leitor não imaginar que o autor se confundiu ou cometeu algum erro de digitação.

${ }_{19}$ AGV, 27.03.1935, CPDOC, GV c 1935.03.27/1.
} 
proposta pelo interventor" ${ }^{20}$, deixando pairar a dúvida sobre se havia, de fato, alguma "fórmula" discutida, fato que acreditamos ser improvável. Afinal, como disse o senador do PRL Simões Lopes, "nenhuma fórmula foi apresentada quer de um lado, quer do outro. O que tem havido foram apenas démarches, mas todas elas de caráter particular, como já por várias vezes se tem divulgado". ${ }^{21}$

Tudo indica que a primeira reunião com representantes da FUG-PRL ocorreu em 29 de março, reunindo Oswaldo Vergara, pelo PRR, Raul Pilla, pelo PL, e Flores da Cunha, pelo PRL. Este encontro foi intermediado por Francisco Barata e Gabriel Pedro Moacyr - que tomara a iniciativa da pacificação política junto com o irmão, Caio Pedro Moacyr, e pertencente ao Partido Libertador, apostando que, "depois de reatadas as relações pessoais, a pacificação do Rio Grande será uma consequência lógica e fatal" (apud ELÍBIO JÚNIOR, 2006, p. 141). Nessa reunião, que, na verdade, ocorreu como consequência do reatamento pessoal de Flores da Cunha com Saldanha, ficou deliberado que os dois partidos oposicionistas consultariam os seus diretórios e, posteriormente, procurariam o interventor, com base naquilo que foi assentado em suas reuniões internas. No dia seguinte, a direção do PRL e PL se reuniram internamente para debater os rumos da pacificação política do estado, que enfrentava a contrariedade de Lusardo, pelo Partido Libertador, e de Borges de Medeiros, "mordido pela vespa do despeito"22, como afirmou Flores da Cunha.

Todavia, as reuniões internas entre PRL e PL deliberaram pelo seguinte: o primeiro, em nota oficial, declarava que a Comissão Diretora "faz ciente aos seus correligionários que, coerente com a resolução tomada no último Congresso do Partido, mantém, como deliberação definitiva, a candidatura do general Flores da Cunha para primeiro governador constitucional do Rio Grande do Sul". Prosseguindo, declarava ver com satisfação "a possibilidade de apaziguamento e

\footnotetext{
${ }^{20}$ Correio do Povo, Porto Alegre, MCSHJC, 26.03.1935.

${ }^{21}$ Correio do Povo, Porto Alegre, MCSHJC, 28.03.1935.

${ }^{22}$ Correio do Povo, Porto Alegre, MCSHJC, 30 e 31.03.1935; 27.07.1935; AAM, 03.04.1935, CPDOC, c AM c 35.04.03/2. Aqui, uma ressalva a Carlos Rangel é necessária. Este autor afirma que as negociações entre a FUG e Flores da Cunha ocorriam desde o exílio dos frenteunistas usando como base essa reunião, dizendo ter ocorrido em 29 de março de 1934, e não em 29 de março de 1935, data certa do encontro. Claro que esse pequeno equívoco não invalida seu excelente estudo sobre a política rio-grandense nos anos 1930, em nossa opinião, uma das melhores bibliografias, mas a alteração do ano muda toda a conjuntura, fato que acabou interferindo na análise realizada por este pesquisador. Cf. RANGEL (2001, p. 182).
} 


\section{Revista Brasileira de História \& Ciências Sociais - RBHCS}

Vol. $8 \mathrm{~N}^{\mathrm{o}}$ 16, Julho - Dezembro de 2016

concórdia na vida política do Rio Grande do Sul, decorrente das 'démarches' que nesse sentido estão sendo realizadas". 23

A declaração oficial do PRL, ao mesmo tempo em que fechava as portas para a principal reivindicação da FUG desde O Discurso no Teatro Coliseu, mostrava o interesse que os governistas possuíam em continuar com as tratativas para um acordo. Por outro lado, para que uma proposta fosse analisada, a manutenção da candidatura de Flores da Cunha era uma exigência irremovível do PRL, destacando a possibilidade de se realizar um acordo que fosse por outros meios.

Nestes termos, o Partido Libertador, após reunião, desapontar-se-ia com a deliberação do PRL. Ainda assim, comprometeu-se a enviar uma carta com sugestões para a "pacificação", após ter entendimentos com o Partido Republicano RioGrandense, de forma que não significasse um acordo entre as correntes. A minuta consistia em onze exigências. Os 11 pontos da FUG foram enviados ao interventor na véspera da instalação da constituinte estadual, que se reuniria em 12 de abril, e era assinado por Raul Pilla e Oswaldo Vergara, representando, cada um, os seus partidos, como já acontecera na reunião de 29 de março.

Lamentando a impossibilidade de um candidato de conciliação, que seria "a verdadeira solução”, e afirmando que “o pensamento dos nossos partidos estava cristalizado no discurso por um de nós pronunciado a 20 de setembro do ano passado, no Teatro Coliseu", afirmava que, "fora da fórmula sugerida, não há, infelizmente, possibilidade de qualquer acordo, compromisso ou combinação política”. Mas, ainda que a FUG considerasse impossível qualquer atendimento com a candidatura Flores da Cunha a governador, ela faria sugestões para sua gestão, dizendo que objetivava "assegurar todas as garantias de ordem e de liberdade, no desempenho do mandato que lhe vai ser outorgado".24 Os pontos propostos, de qualquer modo, constituíam uma clara tentativa de limitar o uso da máquina estatal para fins políticos, visando, dessa forma, a amarrar seu uso pelo florismo, buscando limitar o poder do executivo estadual.

Nos pontos da ata de sugestões a Flores da Cunha, nota-se que elas tinham como finalidade dar maior raio de ação para os frenteunistas nas próximas eleições contra o PRL, retirando o uso da coerção em favor do partido governista. Nesse

${ }^{23}$ Diário de Notícias, Porto Alegre, MCSHJC, 02.04.1935.

24 APRPS/FC, 11.04.1935, AHRGS [caixa sem catálogo]. 


\section{Revista Brasileira de História \& Ciências Sociais - RBHCS}

Vol. $8 \mathrm{~N}^{\mathrm{o}}$ 16, Julho - Dezembro de 2016

sentido, como a violência esteve bastante presente nos dois pleitos, os primeiros itens propunham uma imediata reforma na polícia, onde era notória a tentativa de retirar dela a influência partidária nos prélios eleitorais. Prova disso é que, dos 11 pontos, os cinco primeiros diziam respeito diretamente à necessidade de uma extensa modificação na estrutura policial, ou seja, quase metade da proposta versava sobre esse assunto, prevendo com que a polícia perca o caráter partidário instituindo um plano de carreira; que sua chefia seja exercida por uma pessoa que possua atribuições pessoais e que assegurem isenção e imparcialidade no exercício da função; que fosse suprimida as sub chefaturas de polícia; prevendo a revisão nos quadros da polícia estadual e municipal, visando destituir os funcionários denunciados ou pronunciados pela justiça, ou que fossem, por qualquer outra maneira, considerados inidôneos; e que fossem instaurados inquéritos para a repressão criminal de todos os responsáveis pelo atentados que a FUG alegava ter sofrido. ${ }^{25}$

Essas reformas, caso fossem postas em prática, seriam um duro golpe no florismo. Flores da Cunha não poderia mais nomear policiais aliados ao PRL, deixando a polícia como órgão "neutro". Das propostas, a exclusão das sub-chefaturas de polícia, instaladas no interior do estado, representariam uma perda importante do controle "coronelístico" 26 do interventor, sobretudo se for levado em conta que, no final de 1935, ocorreriam as eleições para prefeituras municipais. Perder o aparato repressivo poderia refletir-se num crescimento ainda mais representativo da FUG, que já vinha em ascendente.

Já os tópicos seguintes propunham reformas na máquina administrativa do estado. Também teriam um viés político, embora não abordassem a questão policial. No sexto ponto, previa-se a redução da despesa pública com a supressão de gastos considerados desnecessários, além de prever a extinção de alguns privilégios fiscais; no sétimo, pautou-se por medidas para garantir o livre exercício das atividades eleitorais e substituir autoridades que, direta ou indiretamente, tenham sido responsáveis por crimes ou violências. Previa também a admissibilidade de funcionários públicos e promoções por meio de concurso e títulos, e não pelo critério

\footnotetext{
${ }^{25}$ ARP, 04.04.1935, NUPERGS, doc. $\mathrm{n}^{0}$ 002/1137.

${ }^{26}$ Coronelismo aqui é entendido como um conjunto de ações políticas realizados por um coronel que, devido ao seu poderio econômico, intelectual ou social, pelo uso da força, prestígio familiar, popularidade e/ou habilidade política, eram investidos do poder de controle nas localidades em que exerciam suas atividades. Influenciavam diretamente na atuação dos poderes públicos instituídos, já que tinham o domínio econômico e social de suas regiões, a fim de possibilitar a manipulação eleitoral em causa própria ou de uma oligarquia a que faziam parte. (LUZ; SANTIN, 2010, p. 8).
} 


\section{Revista Brasileira de História \& Ciências Sociais - RBHCS}

Vol. $8 \mathrm{~N}^{\circ}$ 16, Julho - Dezembro de 2016

partidário, além de readmitir os funcionários afastados por motivos políticos aos mesmos cargos anteriormente ocupados ou equivalentes, somando na antiguidade o tempo em que ficaram afastados, tanto civis como militares. Nos últimos dois tópicos, a FUG defendia a proibição de quem exerce função pública em intervir no pleito eleitoral e na propaganda política, impondo suspensão administrativa e responsabilidade criminal para àquele que viesse a usar do cargo para sugestionar, corromper, intimidar ou violentar qualquer eleitor, devendo ser destituído da função caso seja demissível; e reivindicava que lhe fosse assegurada plena liberdade de imprensa, tribuna e reunião. ${ }^{27}$

Muitas dessas sugestões tinham indiscutível vínculo com as ocorrências desde 1932, como a readmissão de funcionários, ou a ampla liberdade de imprensa, tendo em vista a campanha de hostilidade contra o Correio do Povo pela A Federação, a proibição de suas vendas pelo diretor da Viação Férrea e o incêndio no jornal $O$ Libertador, todos no pleito eleitoral de 1934. Também outros tópicos, como o sétimo, buscavam assegurar punição e investigação a crimes e perseguições anteriores ao pacto. O oitavo ponto buscava a inibição de uma atitude bastante comum, a da nomeação de partidários da facção política situacionista no estado. Afinal, essa prática atrelava o corpo de funcionários do estado a acompanhar o situacionismo, tornando-se seu aliado, e até mesmo servindo de informante, quando determinados funcionários não fossem apoiadores do PRL, sofrendo represálias, como demissões e transferências compulsórias, enquanto a penúltima cláusula anulava qualquer participação do funcionalismo nas questões políticas.

Praticamente, o único envolvimento com política partidária para o qual o funcionalismo teria permissão seria o direito ao voto. Terminaria desta forma o uso desse elemento para arregimentar eleitores, já que até mesmo por medo de demissão ou transferência, o voto e a participação no pleito em prol do partido situacionista era um costume comum. Ou seja, mesmo que a proibição abrangesse FUG e PRL, era este quem teria maior prejuízo, e não aquele. A única pauta que visava a alterações na estrutura governativa sem fins partidários era a sexta. Fato que, por si só, deixava claros os interesses frenteunistas, majoritariamente partidários, por trás dessa proposta.

${ }^{27}$ ARP, 04.04.1935, NUPERGS, doc. $\mathrm{n}^{0}$ 002/1137. 
De qualquer forma, a resposta de Flores da Cunha veio no dia seguinte, relativizando o documento entregue pela Frente Única. Sua réplica reenfatizava as propostas, que eram, em sua visão, apropriadas, e já postas em prática, segundo ele, pelo governo estadual. A reforma radical da organização policial, segundo Flores da Cunha, já era motivo de preocupação do governo, desde quando Florêncio de Abreu era o chefe de polícia estadual (1930), que desejava implantar a polícia de carreira, não tendo sido realizado devido às dificuldades financeiras por que, ainda segundo Flores, passava o estado, naquele momento. Defendia que o governo estadual já vinha comprimindo despesas, e que as atividades eleitorais, amparadas pela nova legislação dos velhos vícios, seriam protegidas por seu governo, assim como a reincorporação dos funcionários exonerados ou transferidos, que já estava prevista na nova carta estadual. Mas, no final, deixava a possibilidade para conversas no futuro, afirmando que os atos passados e os que virão iriam demonstrar "o quanto desejo contribuir para o desarmamento dos espíritos e para o estabelecimento de um período de paz duradoura, que permita ao povo bravo e generoso do Rio Grande do Sul uma existência tranquila e favorável aos surtos de sua evolução moral e material”. ${ }^{28}$

Como podemos perceber, Flores da Cunha não fechava a porta para a FUG, mas também se esquivava em dar uma resposta concreta e incisiva para atender a suas reivindicações. Por outro lado, a Frente Única não cedia em sua exigência. Foi assim que a questão da pacificação ficou morna durante alguns meses. Mesmo que João Neves declarasse para o Diário de Notícias que "o acordo no Rio Grande do Sul [...] está sepultado, e bem fundo!"29, ele, na verdade, logo retornaria bem vivo na pauta dos partidos rio-grandenses.

De toda forma, no dia 15, o interventor foi eleito governador constitucional do Rio Grande do Sul, tendo de cumprir o seu mandato de acordo com aquilo que dizia a nova carta federal e regional, esta, em elaboração pela constituinte. O desacordo, porém, frustrou parte da FUG, e setores que se colocavam contrários ao

\footnotetext{
${ }^{28}$ Diário de Notícias, Porto Alegre, MCSHJC, 13.04.1935. Nesse sentido, a partir do momento em que Flores da Cunha foi eleito governador, obviamente, a pauta de retirar sua candidatura era um desejo impossível. Apesar de ser uma obviedade, alertamos, pois Antônio Elíbio Jr. trouxe, em sua tese, debates que visavam à "pacificação" regional com base no afastamento da candidatura Flores da Cunha, mas que seriam de julho de 1935, período em que ele já era governador do estado. Acreditamos que o autor tenha se equivocado com a data certa das cartas, que ele cita por três vezes. Como o autor não diz em seu trabalho de onde ele retirou essa fonte, somente sublinha: "Carta de Florêncio Machado a Flores da Cunha, 29.07.1935”, em nota de rodapé, não podemos nem ir atrás para checar suas citações com os originais. Cf. ELÍBIO JR (2006, p. 144-145).

${ }_{29}$ Diário de Notícias, Porto Alegre, MCSHJC, 11.04.1935.
} 


\section{Revista Brasileira de História \& Ciências Sociais - RBHCS}

Vol. $8 \mathrm{~N}^{\mathrm{O}}$ 16, Julho - Dezembro de 2016

estabelecimento de uma ditadura militar, ameaça refletida em amotinamentos militares em nível nacional. Nesse sentido, uma missiva de Tancredo Neves, do Rio de Janeiro, para Raul Pilla lamentava o fim das negociações. Analisava ele ser o acordo o único obstáculo que se poderia opor aos males que ameaçavam o Brasil em geral, e o Rio Grande do Sul em especial, enfatizando que a união dos rio-grandenses formaria um entrave para qualquer perturbação da ordem no estado, e que a pacificação política regional já causara pânico entre aqueles que pretendiam aproveitar-se da confusão. Prosseguindo, Tancredo afirmava que o país estava há vários dias sob uma ditadura militar "mascarada", que seria implantada "com todo o cortejo", caso o aumento dos vencimentos aos militares não fosse concedido, pois alegava que isso sobrecarregaria o orçamento, e a única maneira de Getúlio ter condições de vetá-lo sem alteração da ordem política seria com um Rio Grande do Sul unido. Como não seria possível, sugeria que Góis Monteiro substituísse Getúlio, "para que aguente ele com a irresponsabilidade de tal loucura!"3o

Nesse sentido, não somente os setores partidários do Rio Grande do Sul, mas também as classes econômicas tomaram parte no processo de negociações. Em 2 de abril, quinze sindicatos vinculados ao setor produtivo da economia rio-grandense enviavam um documento aos chefes partidários do Rio Grande do Sul, parabenizando o "gesto nobre que tiveram, aproximando-se no sentido de conciliar a família riograndense. [...]. Eis porque fazemos ardentes votos para que, desaparecendo dissídios e resentimentos [sic], todos coloquem os altos interesses do Brasil acima dos interesses pessoais". Pedia que fossem deixadas de lado "as prevenções pessoais, desprezem-se as intrigas e, pela grandeza do Brasil, marchem todos, lado a lado, unidos no grande ideal". ${ }^{31}$ Essa nota, publicada na imprensa estadual, era assinada por diversas federações e associações industriais e rurais. De todo modo, aquilo que está claro para nós e que queremos ressaltar ao leitor deste texto é o fato de que o tema ganhava grande amplitude, e teria implicações no contexto nacional e, regionalmente, interessava à sociedade civil de forma ampla.

Não é a toa que, apesar da negativa em 1935, o assunto tomaria vulto a partir de setembro deste mesmo ano, com uma fórmula defendida por Raul Pilla e José Maria dos Santos, de caráter parlamentarista, enviada a Getúlio Vargas. Com a recusa

${ }^{30}$ ARP, 16.04.1935, NUPERGS, doc. $n^{0}$ 002/1138.

${ }^{31}$ Diário de Notícias, Porto Alegre, MCSHJC, 04.04.1935. 


\section{Revista Brasileira de História \& Ciências Sociais - RBHCS}

Vol. $8 \mathrm{~N}^{\circ}$ 16, Julho - Dezembro de 2016

do presidente da república, caberia a FUG propor para Flores da Cunha esta fórmula em nível regional. Por meio disso, a aproximação definitiva foi viável, assinando, em janeiro de 1936, o acordo denominado de modus vivendi que, apesar da euforia inicial, durou apenas nove meses. O modus vivendi acabou eclodindo devido ao desgaste entre as duas correntes e o trabalho de Getúlio Vargas que, já rompido com Flores da Cunha, trabalhava para isolar politicamente o governador do Rio Grande do Sul.

\section{CONSIDERAÇÕES FINAIS}

Destarte, do que apresentamos neste artigo, procuramos tentar compreender e analisar a conjuntura que levou a Frente Única Gaúcha e Flores da Cunha a buscarem uma "pacificação" da política regional, bem como o que levou o debate inicial, pautado em meio à conjuntura eleitoral de 1934, a tornar-se menos conflituoso, levando ambas as correntes a dialogarem no início de 1935 sem, contudo, chegarem a um acordo.

Podemos perceber, portanto que, apesar de não ter logrado sucesso no momento analisado por este artigo, acreditamos que esta etapa foi fundamental para que a aproximação efetiva, ocorrida em 17 de janeiro de 1936, tivesse ocorrido, fatiando a administração estadual entre o Partido Republicano Liberal, o Partido Libertador e o Partido Republicano Rio-grandense. Este "fracasso", como podemos perceber, decorreu especialmente do fato de os frenteunistas exigirem como moeda de troca a renúncia da candidatura Flores da Cunha a governador constitucional do estado.

A exigência se dava pelo fato de a FUG ter eleito menos parlamentares para a constituinte estadual de 1935 do que o PRL, fato que assegurava a eleição de Flores da Cunha soberanamente. Já que os frenteunistas não conseguiram, pela via eleitoral, defrontar numericamente com os republicanos liberais, restou aos primeiros barganhar com o desejo de Flores da Cunha em pacificar a política regional, como forma de retirar do comando político aquele que era um dos poucos interventores que permaneceriam a frente de um estado desde o movimento revolucionário de 1930. 
Outro fator motivador deste estudo é o fato de poucos trabalhos, sob a ótica da história política, deterem-se ao cenário político rio-grandense, exceção dada, em parte, ao período que abrange o Estado Novo, onde um número razoável de estudos se voltaram para as interventorias dos anos 1937-1945. Portanto, visamos também contribuir nesse quesito, aprofundando os estudos regionais no tema.

\section{REFERÊNCIAS}

AMADO, Janaína. História e região: reconhecendo e construindo espaços. In: SILVA, Marcos A. da. (dir.). República em Migalhas: história regional e local. São Paulo: Marco Zero, 1990, pp. 7-15.

BERSTEIN, Serge. Os partidos. In: REMOND, René. (org.). Por uma história política. Rio de Janeiro: Editora FGV, 2003, pp. 57-98.

CHARAUDEAU, Patrick. Discurso político. São Paulo: Contexto, 2004.

CORTÉS, Carlos E. Política Gaúcha (1930-1964). Porto Alegre: EDIPUCRS, 2007.

COUTINHO, Lourival. O General Góes depõe... Rio de Janeiro: Livraria Editora Coelho Branco, 1956.

ELÍBIO JÚNIOR, Antônio Manoel. A construção da liderança política de Flores da Cunha: Governo, História e Política. Tese (Doutorado em História), Universidade Estadual de Campinas, Campinas, 2006.

LAPUENTE, Rafael Saraiva. 'Estou forte e manterei a ordem. Reagiremos!': um estudo a respeito da política rio-grandense por meio da 'revolução' de 1932. Revista do Instituto Histórico e Geográfico. Porto Alegre, n. 149, pp. 129-147, dez. 2015.

LUZ, Alex Faverzani; SANTIN, Janaina Rigo. As disputas pelo poder local no Brasil durante o regime coronelista e a reorganização do Estado. Jurisvox. Patos de Minas, v.1, $\mathrm{n}^{\mathrm{O}}$ 11, pp. 7-19 nov. 2010.

MOTTA, Rodrigo Patto Sá. Introdução à história dos partidos políticos brasileiros. Minas Gerais: UFMG, 1999.

MOURELLE, Thiago Cavaliere. Guerra pelo poder: a Câmara dos Deputados confronta Vargas (1934-1935). Tese (Doutorado em História), Universidade Federal Fluminense, Niterói, 2015.

RANGEL, Carlos Roberto da Costa. Crime e Castigo: Conflitos Políticos no Rio Grande do Sul. Passo Fundo: EDIUPF, 2001. 
RECKZIEGEL, Ana Luiza Setti. Apresentação. In: BATISTELLA, Alessandro et al (orgs.). Fazendo História Regional: política e cultura. Passo Fundo: Méritos, 2010, pp. 5-8.

TRINDADE, Hélgio. A Revolução de 1930: Partidos e imprensa partidária no Rio Grande do Sul. Porto Alegre: L\&PM, 1980.

VARGAS, Getúlio. Diário (1930-1936). São Paulo: Siciliano; Rio de Janeiro: Fundação Getúlio Vargas, 1995, v. I.

\section{ARQUIVOS}

ARQUIVO ANTUNES MACIEL (AAM) - CPDOC/FGV

ARQUIVO FLORES DA CUNHA (AFC) - NUPERGS/UFRGS

ARQUIVO GETÚLIO VARGAS (AGV) - CPDOC/FGV

ARQUIVO PARTICULAR REGINA PORTELLA SCHNEIDER (APRPS/FC)ARQUIVO HISTÓRICO DO RIO GRANDE DO SUL (AHRGS).

ARQUIVO PARTICULAR SINVAL SALDANHA/BORGES DE MEDEIROS (APSS/BM) - ARQUIVO HISTÓRICO DO RIO GRANDE DO SUL (AHRGS).

ARQUIVO RAUL PILLA (ARP) - NUPERGS/UFRGS

MUSEU DE COMUNICAÇÃO SOCIAL HIPÓLITO JOSÉ DA COSTA (MCSHJC)DIÁRIO DE NOTÍCIAS/CORREIO DO POVO.

HEMEROTECA DIGITAL DA BIBLIOTECA NACIONAL - A FEDERAÇÃO 